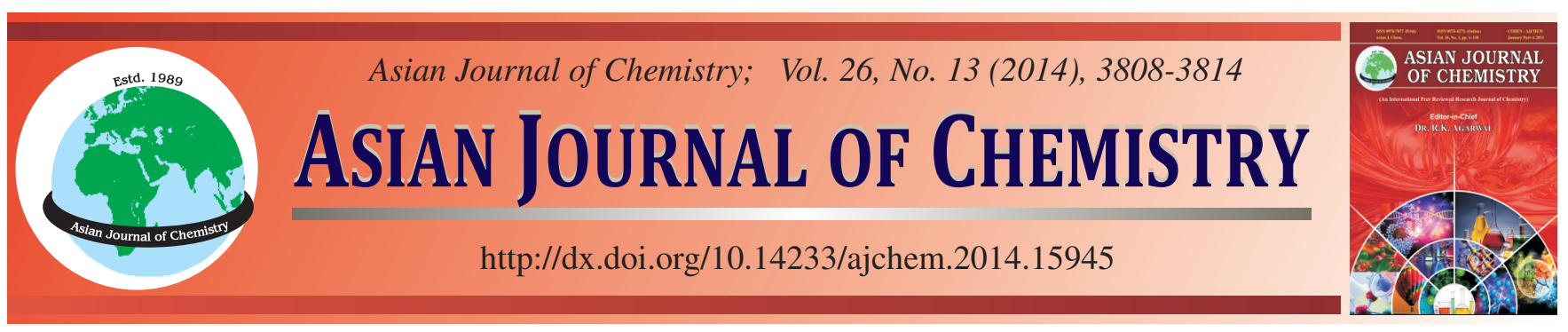

\title{
Removal of Basic Blue 3 Dye Using Pomelo Peel
}

\author{
SHU-WeI LiEW ${ }^{1}$ and Siew-Teng ONG ${ }^{1,2 *}$
}

${ }^{1}$ Department of Chemical Science, Faculty of Science, Universiti Tunku Abdul Rahman, Jalan Universiti, Bandar Barat, 31900 Kampar, Perak, Malaysia

${ }^{2}$ Centre for Biodiversity Research, Universiti Tunku Abdul Rahman, Jalan Universiti, Bandar Barat, 31900 Kampar, Perak, Malaysia

*Corresponding author: Fax: +60 5 4661676; E-mail: ongst@utar.edu.my; ongst_utar@yahoo.com

A low-cost adsorbent pomelo peel was investigated for its potential and feasibility to remove basic blue 3 dye from aqueous solutions. Different parameters such as initial dye concentrations, contact time and $\mathrm{pH}$ were used to examine its adsorption behaviour. The percentage removal of dye increased as decreasing in the initial dye concentrations and the attainment equilibrium of the adsorption system could be achieved in $4 \mathrm{~h}$. When the experimental data were further studied by the kinetic models, it was evident that the pseudo-second-order kinetic model provided higher correlation coefficient $\left(\mathrm{R}^{2}>0.9960\right)$ for the adsorption system. The effect of solution $\mathrm{pH}$ on dye uptake revealed that the percentage removal of dyes increased when the solution $\mathrm{pH}$ was increased. Adsorption of basic blue 3 dye onto pomelo peel fitted well to the Freundlich isotherm models, with high correlation coefficient of 0.9914. Based on Langmuir equation, the maximum adsorption capacity of pomelo peel was $23.87 \mathrm{mg} / \mathrm{g}$.

Keywords: Immobilization, Pomelo peel, Adsorption, Basic blue 3.

\section{INTRODUCTION}

Dyes are generally used in many industries such as textile, paper and paint. Besides being used as colouring agents, they play an important role in the high-tech applications. Examples of which are light-emiting diodes and laser welding processes ${ }^{1}$. Due to the wide applications of dyes for different purposes, an annual production of $7.0 \times 10^{5}$ tonnes of various dyes is required to meet the demand ${ }^{2}$. An estimated $2.8 \times 10^{5}$ tonnes of dyestuffs are disposed yearly ${ }^{3}$.

Basic blue 3 (BB3) is one of the azo dyes. Azo dyes which contains one or more nitrogen to nitrogen double bonds $(-\mathrm{N}=\mathrm{N}-)$ constitute a major part of all commercial dyes. Under anaerobic condition, aromatic amines are produced as a result of the reduction of cleavage of azo linkages ${ }^{3}$. The final product of the reaction is toxic to the living organisms. Hence, a proper management of the dye-containing wastewater is strictly needed and strongly recommended before disposal into the water streams.

Liquid-adsorption is characterized as the most efficient methods for the removal of colours, odors, organic and inorganic pollutants from industrial effluents ${ }^{1,4}$. This type of treatment method is popular and attractive nowadays due to the high adsorption efficiency and effectiveness in removing dyes from dye-containing wastewater in comparison to other physical and biological treatments methods. Also, adsorption technique is simple and flexible and subsequently can be operated easily. Most importantly, there are no toxic and harmful by-products being generated which can cause environmental problems.

In view of applicability of adsorption process, the cost of adsorbents to be used is a most critical restricted factor. Commercial activated carbon (CAC), generally prepared from coal, is well-known for its high adsorption abilities for the treatment of a wide range of synthetic dyes, which can be either cationic nor anionic. However, the production and regeneration costs of $\mathrm{CAC}$ are high and disposal of the toxic by-products generated after adsorption can cause environmental problems ${ }^{5}$. As a consequence, many researchers have paid their attentions on the potential and feasibility of the use of readily available low-cost absorbents obtaining from industrial and agricultural areas to treat highly toxic and coloured synthetic-dye-containing wastewater. A wide variety of lowcost adsorbents have been examined, for example, palm kernel fibre $^{6}$, fruits peel ${ }^{7}$, jackfruit peel ${ }^{8}$, coconut bunch waste ${ }^{9}$, hazelnut shell ${ }^{10}$, coffee residues ${ }^{11}$, duckweed ${ }^{12}$, sugarcane bagasse ${ }^{13}$ and cotton stalk, cotton waste and cotton dust $\mathrm{t}^{14}$.

In this research, pomelo fruits were chosen as the adsorbent. Pomelo (Citrus maxima of Citrus grandis), also known as pummelo, shaddock or Chinese grapefruit, originates from 
southestern Asia and all of Malaysia. An approximately 8.83 $\times 10^{2}$ metric tons of pomelo fruits is produced yearly from about $1.9 \times 10^{2}$ ha of pomelo trees in Malaysia ${ }^{15}$. Pomelo fruit, rich in vitamin $\mathrm{C}$ and flavonoids, is usually eaten fresh. Besides being processed to produce jams, marmalade and fruit cocktails in food industry, they are used to make desserts and salads in our daily lives. Since pomelo fruits are highly consumed, there is a great amount of the peels being discarded. These disposed wastes to the environment without fully utilizing them can subsequently cause negative impacts to community such as disposal and environmental problems. Hence, to overcome all these problems, it is suggested that pomelo peels should be studied to examine whether it is suitable to be used as a lowcost adsorbent. Besides increasing the value of the waste products, it can help to reduce the water pollution by adsorption of dye-containing wastewater. The main disadvantage of a suspended system is that it requires a filtration step which is not suited for practical applications. Therefore, a feasible approach to overcome this obstacle was attempted in this research and that is to immobilize the adsorbent onto a supporting material.

\section{EXPERIMENTAL}

Sorbent: Pomelo peels (PP) were collected from a local market. The collected pomelo peels was washed several times using tap water to remove all the dirt particles before rinsing with distilled water. The washed materials were subsequently cut into small pieces $(1-2 \mathrm{~cm})$ and dried in an oven at $60{ }^{\circ} \mathrm{C}$ for $48 \mathrm{~h}$ to ensure the removal of moisture content. The dried peels were then ground and passed through a sieve to obtain particle sizes ranging $0.5-1 \mathrm{~mm}$. The plastic container containing the powdered form of pomelo peel was kept in a dessicator for further use.

Sorbate: In this research, basic blue 3 dye (BB3) was used without further purification as the adsorbate. The cationic dye basic blue 3 has a molecular weight of $359.89 \mathrm{~g} / \mathrm{mol}$ and its molecular structure was illustrated in Fig. 1. The dye powder was purchased from Sigma-Aldrich Pvt. Ltd. (United States of America). A stock solution with the concentration of 1000 $\mathrm{mg} / \mathrm{L}$ was prepared and subsequently diluted to attain the desired concentration when necessary.

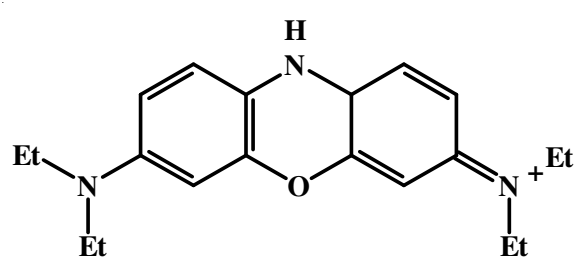

Fig. 1. Basic blue 3 dye molecule

Immobilization of dried pomelo peel on glass plates: $5.0 \mathrm{~g}$ of dried pomelo peel was weighed and immobilized onto the glass plates $\left(2.5^{\prime \prime} \times 1.0^{\prime \prime} \times 0.1^{\prime \prime}\right)$ before the adsorption experiments.

Scanning electron microscopy (SEM): The surface morphology of pomelo peel (before and after adsorption) was examined using FESEM JSM 6701F (JEOL).
Fourier transform infrared spectrophotometry (FTIR): Fourier transform infrared spectrophotometry analysis was used to examine the functional groups that present on pomelo peel surface. FTIR analysis of pomelo peel in the solid phase was performed using Perkin-Elmer System 2000 FT-IR Spectrometer.The powdered form pomelo peel solid sample was mixed with IR-grade potassium bromide $(\mathrm{KBr})$ in a mortar and pestle. The mixture was then subjected to high pressure using a hydraulic $\mathrm{KBr}$ press to melt the $\mathrm{KBr}$ and seal the compound into matrix. The small disk obtained was analyzed using FITR spectrometer.

Batch adsorption studies: In this study, all the experiments were carried out at room temperature $\left(25 \pm 2{ }^{\circ} \mathrm{C}\right)$ to eliminate any temperature effects on the adsorption of basic blue 3 dye onto pomelo peel. A volume of $2 \mathrm{~L}$ basic blue 3 dye solution was poured into the reactor. Eight glass plates coated with pomelo peel with a total weight of $5 \mathrm{~g}$ were used each time. Natural $\mathrm{pH}$ of basic blue 3 dye was applied for all of the experiments unless otherwise stated. The dye solutions were collected using a syringe and then analyzed with UVvisible spectrophotometer to measure their absorbance corresponding to a maximum wavelength of $654 \mathrm{~nm}$.

The percentage removal of basic blue 3 dye was determined from the following equation:

$$
\operatorname{Uptake}(\%)=\frac{\left(\mathrm{C}_{\mathrm{o}}-\mathrm{C}_{\mathrm{t}}\right)}{\mathrm{C}_{\mathrm{o}}} \times 100
$$

where $\mathrm{C}_{\mathrm{o}}$ and $\mathrm{C}_{\mathrm{t}}(\mathrm{mg} / \mathrm{L})$ are the liquid-phase concentrations of dye at initial and equilibrium, respectively.

Effect of initial concentration and contact time: The synthetic dye solution was agitated for $8 \mathrm{~h}$ by bubbling air through the reaction system. The samples were collected at predetermined intervals $(0.5,1,3,5,10,15,30,60,90,120$, 180, 240, 300, 360, 420, 480 minutes). The experiment was repeated by using 30 and $40 \mathrm{mg} / \mathrm{L}$ of basic blue 3 dye solutions.

Effect of pH: The effect of $\mathrm{pH}$ on adsorption of basic blue 3 dye onto pomelo peel was examined by equilibrating adsorption-mixture in the $\mathrm{pH}$ ranging from 2, 4, 6, 8 and 10 . Adjustment of the initial $\mathrm{pH}$ of the dye solutions was made by adding various molarity of $\mathrm{HCl}$ and $\mathrm{NaOH}$ dropwise prior to adsorption experiments. The synthetic dye solution was agitated for $4 \mathrm{~h}$ by bubbling air through the reaction system. Samples were collected after $4 \mathrm{~h}$ and the solution $\mathrm{pH}$ was measured.

Sorption isotherm: The dye solution with different concentrations, 30, 50, 70 and $90 \mathrm{mg} / \mathrm{L}$ were prepared and equilibrated for $4 \mathrm{~h}$. The final dye concentration was then analyzed using UV-visible spectrophotometer.

\section{RESULTS AND DISCUSSION}

Scanning electron micrograph (SEM): Fig. 2(a) and (b) shows the SEM micrographs of pomelo peel before and after adsorption, respectively. Based on Fig. 2(a), it was found that the surface of the pomelo peel belongs to a non-porous type. After adsorption, the dye-loaded on the surface of pomelo peel appeared to be slightly different, whereby it is considered much smoother and flat as shown in Fig. 2(b). 

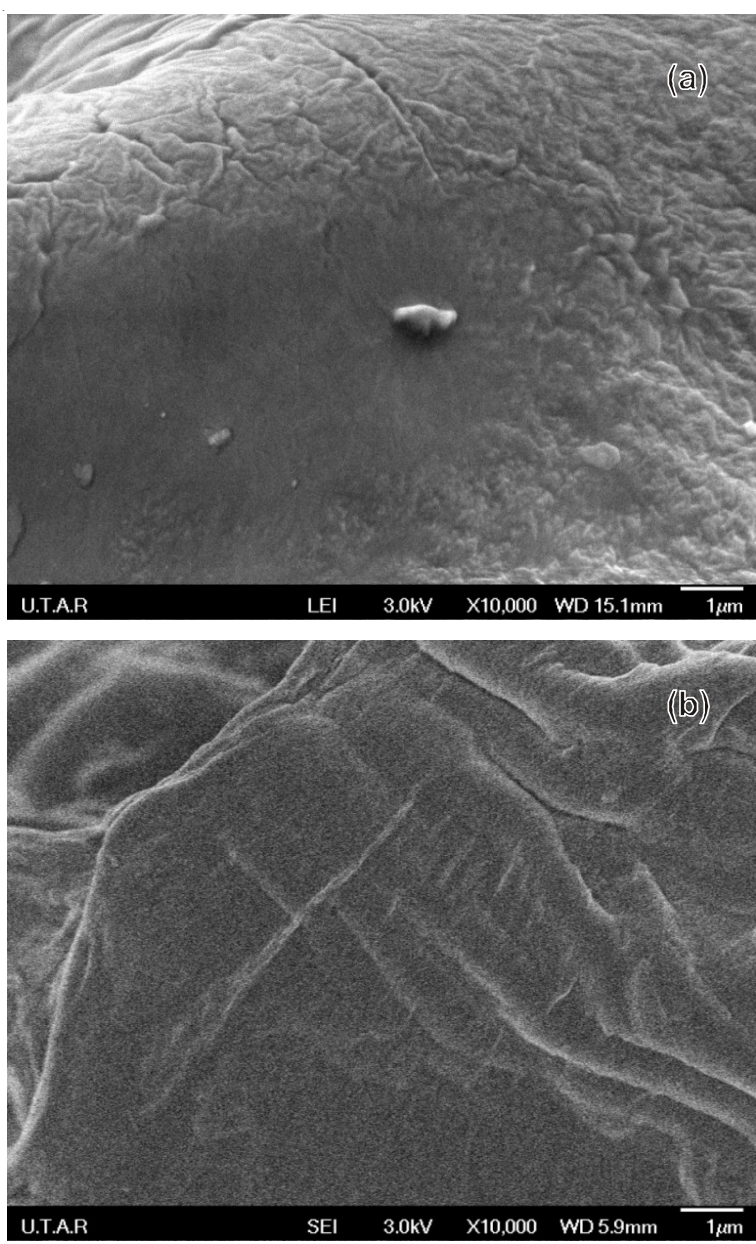

Fig. 2. (a) and (b): SEM micrographs of pomelo peel with magnifications of $10000 \times$

Fourier transform infrared spectrophotometery (FITR): On the basis of characterization, FTIR analysis is essential in order to identify the functional groups of pomelo peel that is responsible for dye binding. Fig. 3 shows the FTIR spectrum of pomelo peel samples before adsorption of basic blue 3 dye in the range of $4000-400 \mathrm{~cm}^{-1}$. Based on the FTIR spectrum, a strong adsorption was observed in the region 3600$3200 \mathrm{~cm}^{-1}$. It may be because of the presence of the hydroxyl group of pomelo peel. The peak at $2929 \mathrm{~cm}^{-1}$ could be attributed to $\mathrm{O}-\mathrm{H}$ stretching vibrations. The sharp band appeared at 1744 $\mathrm{cm}^{-1}$ corresponded to the $\mathrm{C}=\mathrm{O}$ stretching from the lignin carbonyl groups ${ }^{16}$. In addition, the peaks observed at 1631 $\mathrm{cm}^{-1}$ and $1378 \mathrm{~cm}^{-1}$ could be associated with $\mathrm{C}=\mathrm{C}$ stretching and salts of carboxylic acids, respectively. A band at $1063 \mathrm{~cm}^{-1}$ was due to $\mathrm{C}-\mathrm{O}-\mathrm{H}$ which indicated the presence of lignin structure in pomelo pee ${ }^{16}$.

Effect of initial concentration and contact time: The effect of initial dye concentrations and contact time on uptake of basic blue 3 dye solution by pomelo peel was studied and the result was presented in Fig. 4. The percentage of dye uptake decreased as the concentrations was increased. The adsorption was fast over the first $30 \mathrm{~min}$ and it proceeded at a slower rate until the attainment of equilibrium at $480 \mathrm{~min}$. A similar trend was observed in the removal of dye molecules by other adsorbents such as hazelnut shell ${ }^{10}$, palm kernel fibre ${ }^{6}$, papaya seeds ${ }^{17}$ and rejected tea ${ }^{18}$.

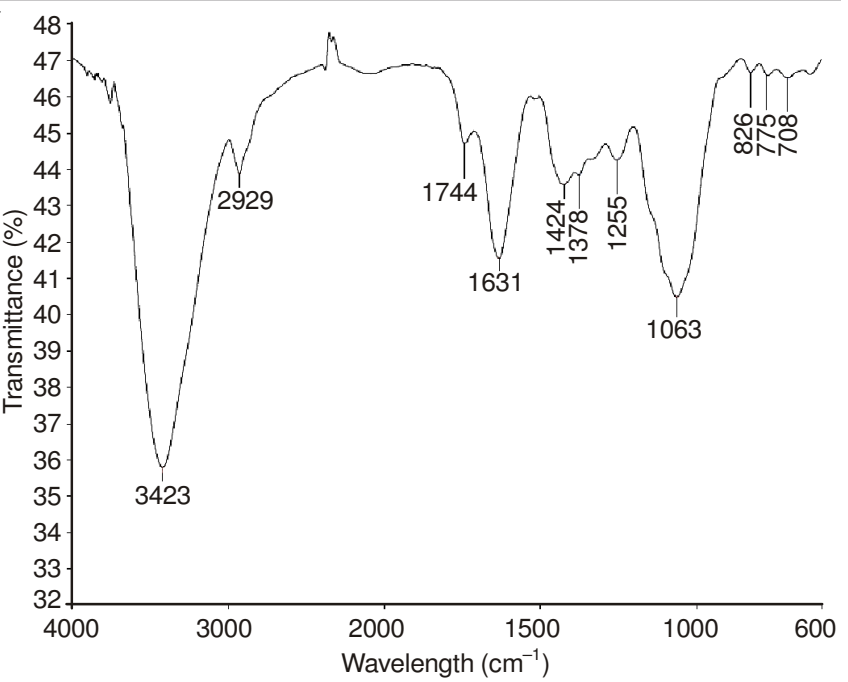

Fig. 3. FT-IR spectrum of pomelo peel

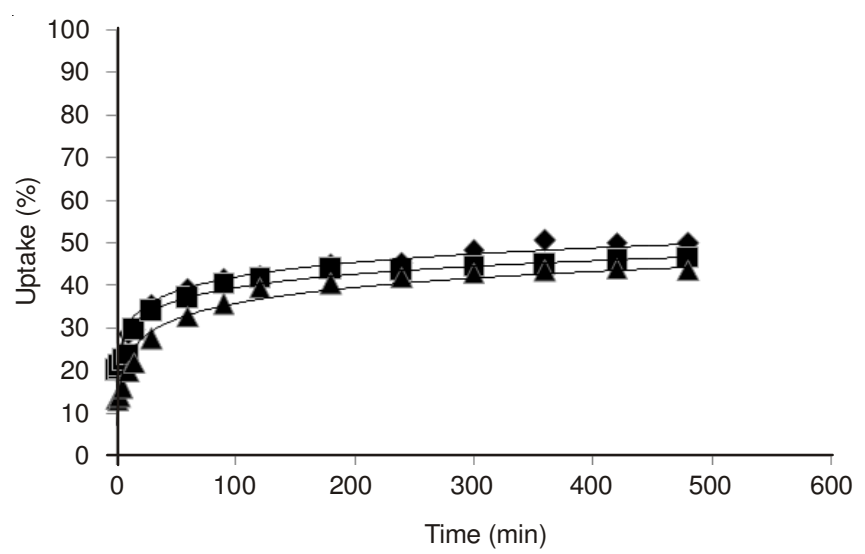

Fig. 4. Effect of initial basic blue 3 dye concentrations and contact time on the percentage uptake of basic blue 3 by pomelo peel. $\mathbf{\square}, \mathbf{\Lambda}$ 20,30 and $40 \mathrm{mg} / \mathrm{L}$ of basic blue 3 (5.0 g pomelo peel; dye volume $2 \mathrm{~L}$; natural $\mathrm{pH}$ of dye solution; $8 \mathrm{~h}$ )

As shown in Fig. 4, the percentage uptake increased with increasing contact time till the attainment of equilibrium. The rapid uptake at first 30 min was greatly due to the availability of a high amount of vacant active sites. A slower adsorption was found with increasing contact time. This is because time taken for the penetration of the basic blue 3 dye molecules to the inner active sites of pomelo peel was longer and hence an insignificant adsorption was shown in the second stage of the system.

It has been postulated that in an adsorption process, it involved three stages. First of all, film mass transfer where the diffusion of dye molecules in the solution to the outer surface of the adsorbent occurred. At the second stages, dye molecules had to penetrate through the pores of the inner structure of pomelo peel. It was time-consuming prior to the attainment of equilibrium. Finally, the accumulation of basic blue 3 dye molecules on the empty active sites on inner surface of the negatively-charged adsorbent was found.

As increasing contact time, it was found that the adsorption of dye solutions of different concentrations attained equilibrium at different time. At low concentration $(20 \mathrm{mg} / \mathrm{L})$, approximately $180 \mathrm{~min}$ was required for the system to reach equilibrium. The time required for the attaining equilibrium was $240 \mathrm{~min}$ and $300 \mathrm{~min}$ for dye solutions with concentrations 
of 30 and $40 \mathrm{mg} / \mathrm{L}$, respectively. The experimental data indicated that the initial concentration and contact time exerted a noticeable influence on the adsorption process of basic blue 3 dye onto pomelo peel.

Kinetic studies: Adsorption kinetic study in wastewater treatment is important as information regarding the reaction mechanism of adsorption is provided, which is in turn vital for the efficiency of the process optimization. In addition, adsorption kinetics revealed a large dependence on the physical and chemical characteristics of the adsorbent which also influences the adsorption mechanism ${ }^{19}$.

In this study, the adsorption kinetic of the adsorption of basic blue 3 dye onto pomelo peel was monitored by applying two commonly used kinetic models, namely, pseudo-firstorder $^{20}$ and pseudo-second-order ${ }^{21}$. The linear equations are expressed as follows:

$\log \left(\mathrm{q}_{\mathrm{e}}-\mathrm{q}_{\mathrm{t}}\right)=\log \mathrm{q}_{\mathrm{e}}-\mathrm{k}_{1} \mathrm{t} / 2.303$ (pseudo-first order equation) (2)

$$
\mathrm{t} / \mathrm{q}_{\mathrm{t}}=1 / \mathrm{h}+\mathrm{t} / \mathrm{q}_{\mathrm{e}} \text { (pseudo-second order equation) }
$$

where $\mathrm{q}_{\mathrm{e}}=$ the amount of dye adsorbed at equilibrium $(\mathrm{mg} / \mathrm{g})$, $\mathrm{q}_{\mathrm{t}}=$ the amount of dye adsorbed at time $\mathrm{t}(\mathrm{mg} / \mathrm{g}), \mathrm{k}_{1}=$ the rate constant of pseudo-first order kinetics $\left(\min ^{-1}\right), \mathrm{h}\left(\mathrm{k}_{2} \mathrm{q}_{\mathrm{e}}{ }^{2}\right)=$ the initial absorption rate, $(\mathrm{mg} / \mathrm{g} \min )$ and $\mathrm{k}_{2}=$ the rate constant of pseudo-second order kinetics ( $\mathrm{g} / \mathrm{mg} \min$ )

Values of the first-order rate constant $\left(\mathrm{k}_{1}\right)$ and theoretical value of $\mathrm{q}_{\mathrm{e}}$ can be obtained respectively from the slope and the $y$-intercept of the linear plots of $\log \left(\mathrm{q}_{\mathrm{e}}-\mathrm{q}_{\mathrm{t}}\right)$ against time for the adsorption of basic blue 3 dye of initial concentration of 20, 30 and $40 \mathrm{mg} / \mathrm{L}$ (Fig. 5). It was found that the pseudo-first order kinetic model did not fit well for the whole range of concentrations studied as the equilibrium adsorption capacities calculated from this kinetic model gave unreasonable values compared to those determined experimentally (Table-1). Since the $\mathrm{R}^{2}$ values were greater than 0.9960 for all cases, this indicated that the pseudo-second-order kinetic order model provided a better correlation of the experimental data compared to that of pseudo-first-order kinetic order model (Table-1).

The initial adsorption rate $(h)$ and theoretical value of $\mathrm{q}_{\mathrm{e}}$ were determined from the y-intercept and the slope of the plot of the linear plot of $t / q_{t}$ against $t$ for the adsorption of basic blue 3 dye of initial concentration of 20,30 and $40 \mathrm{mg} / \mathrm{L}$ (Fig. 6), respectively. To determine $\mathrm{k}_{2}$ values, $\mathrm{h}$ and $\mathrm{q}_{\mathrm{e}}$ values were substituted into eqn. 4 . The initial adsorption rate, $\mathrm{h}(\mathrm{mg} /$ $\mathrm{g} \min )$ at $\mathrm{t} \rightarrow 0$ was expressed as:

$$
\mathrm{h}=\mathrm{k}_{2} \mathrm{q}^{2}
$$

Based on Table-1, the theoretical $q_{e, c a l}$ values were in close agreement with the experimental $\mathrm{q}_{\mathrm{e}, \exp }$ values at different initial basic blue 3 dye concentrations. This indicated the adsorption kinetics of basic blue 3 dye onto the pomelo peel adsorbent

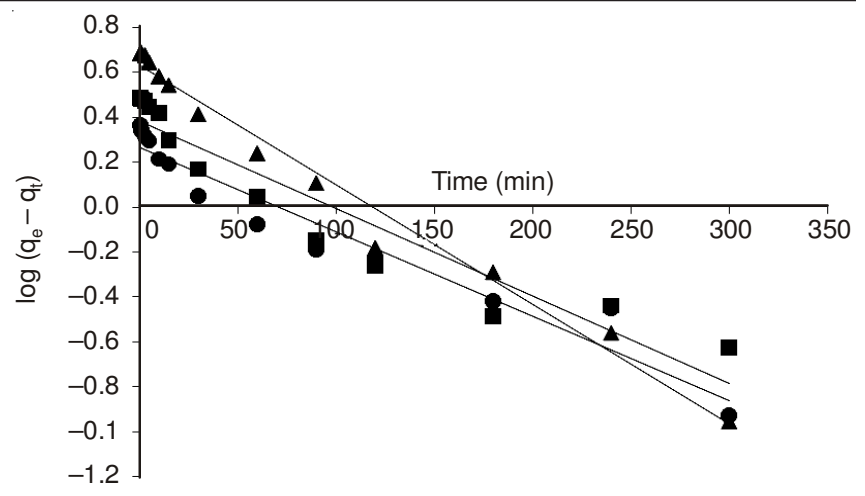

Fig. 5. Pseudo-first-order plot for the adsorption of basic blue 3 onto pomelo peel. $\mathbf{\square}, \boldsymbol{\Delta}-20,30$ and $40 \mathrm{mg} / \mathrm{L}$ of basic blue $3(5.0 \mathrm{~g}$ pomelo peel; dye volume $2 \mathrm{~L}$; natural $\mathrm{pH}$ of dye solution; $8 \mathrm{~h}$ )

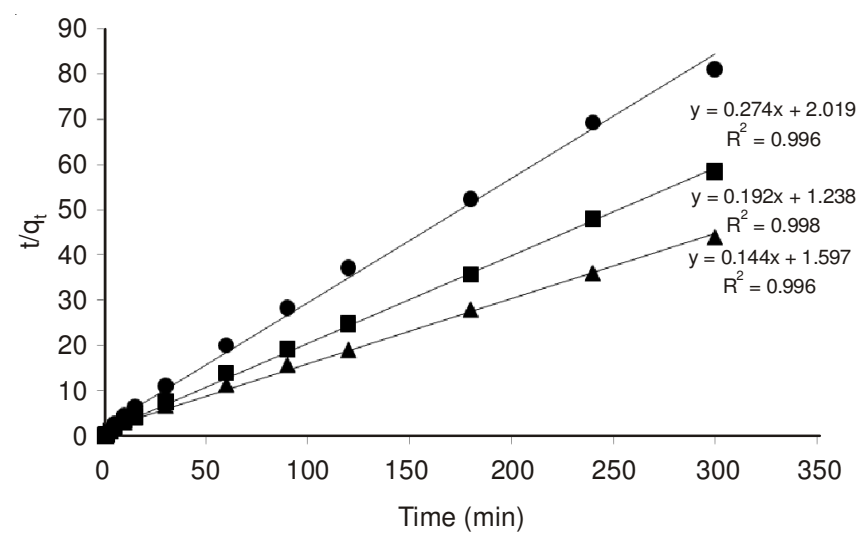

Fig. 6. Pseudo-second-order plot for the adsorption of basic blue 3 dye onto pomelo peel. $\mathbf{\square}, \mathbf{\Delta}-20,30$ and $40 \mathrm{mg} / \mathrm{L}$ of basic blue 3 ( $5 \mathrm{~g}$ pomelo peel; dye volume $2 \mathrm{~L}$; natural $\mathrm{pH}$ of dye solution; $8 \mathrm{~h}$ )

was well described by pseudo-second-order kinetic model. It is suggested that chemisorption occurs involving valency forces through sharing or the exchange of electrons between the adsorbate and the adsorbent $\mathrm{t}^{22}$.

The values of $\mathrm{k}_{2}$, $\mathrm{h}$ and $\mathrm{q}_{\mathrm{e}}$ against $\mathrm{C}_{\mathrm{o}}$ in the corresponding linear plots of the pseudo-second-order kinetic model equation were regressed to obtain expressions for these values in terms of the initial basic blue 3 dye concentrations ${ }^{21}$. These parameters could be presented as a function of $\mathrm{C}_{\mathrm{o}}$ for dye on pomelo peel as follows:

$$
\begin{aligned}
\mathrm{q}_{\mathrm{e}} & =\frac{\mathrm{C}_{\mathrm{o}}}{\mathrm{A}_{\mathrm{q}} \mathrm{C}_{\mathrm{o}}+\mathrm{B}_{\mathrm{q}}} \\
\mathrm{k}_{2} & =\frac{\mathrm{C}_{\mathrm{o}}}{\mathrm{A}_{\mathrm{k}} \mathrm{C}_{\mathrm{o}}+\mathrm{B}_{\mathrm{k}}} \\
\mathrm{h} & =\frac{\mathrm{C}_{\mathrm{o}}}{\mathrm{A}_{\mathrm{h}} \mathrm{C}_{\mathrm{o}}+\mathrm{B}_{\mathrm{h}}}
\end{aligned}
$$

\begin{tabular}{|c|c|c|c|c|c|c|c|c|}
\hline \multirow{2}{*}{$\begin{array}{l}\text { Initial basic blue } 3 \\
\text { dye concentration } \\
\qquad\left(\mathrm{mg} \mathrm{L}^{-1}\right)\end{array}$} & \multirow[b]{2}{*}{$\begin{array}{c}\mathrm{q}_{\text {e. exp }} \\
\left(\mathrm{mg} \mathrm{g}^{-1}\right)\end{array}$} & \multicolumn{3}{|c|}{ Pseudo-first order kinetic model } & \multicolumn{4}{|c|}{ Pseudo-second order kinetic model } \\
\hline & & $\mathrm{q}_{\mathrm{e}, \mathrm{cal}}\left(\mathrm{mg} \mathrm{g}^{-1}\right)$ & $\mathrm{k}_{1}\left(\min ^{-1}\right)$ & $\mathrm{R}^{2}$ & $\mathrm{q}_{\mathrm{e}, \text { cal }}\left(\mathrm{mg} \mathrm{g}^{1}\right)$ & $\begin{array}{c}\mathrm{k}_{2}\left(\mathrm{~g} \mathrm{mg}^{-1}\right. \\
\left.\min ^{-1}\right)\end{array}$ & $\begin{array}{c}\mathrm{h}\left(\mathrm{mg} \mathrm{mg}^{-1}\right. \\
\left.\min ^{-1}\right)\end{array}$ & $\mathrm{R}^{2}$ \\
\hline 20 & 3.8218 & 1.8348 & 0.00875 & 0.9443 & 3.6443 & 0.03728 & 0.4951 & 0.9965 \\
\hline 30 & 5.3782 & 2.4021 & 0.00898 & 0.9040 & 5.1840 & 0.03004 & 0.8074 & 0.9986 \\
\hline 40 & 6.9407 & 4.2599 & 0.01221 & 0.9823 & 6.9348 & 0.01302 & 0.6262 & 0.9961 \\
\hline
\end{tabular}

TABLE-1

PSEUDO-FIRST ORDER AND PSEUDO-SECOND ORDER KINETIC MODEL PARAMETERS FOR DIFFERENT INITIAL BASIC BLUE 3 DYE CONCENTRATIONS 
where $A_{q}, B_{q}, A_{k}, B_{k}, A_{h}$ and $B_{h}$ are constant for the respective equations. The constant values can then be determined from the slopes and intercepts of the linear plots accordingly (Table-2).

\begin{tabular}{cccccc}
\multicolumn{7}{c}{ TABLE-2 } \\
EMPIRICAL PARAMETERS FOR \\
\hline $\begin{array}{c}\mathrm{A}_{\mathrm{a}} \\
\left(\mathrm{g} \mathrm{mg}^{-1}\right)\end{array}$ & $\begin{array}{c}\mathrm{B}_{\mathrm{a}} \\
\left(\mathrm{g} \mathrm{L}^{-1}\right)\end{array}$ & $\begin{array}{c}\mathrm{A}_{\mathrm{k}}\left(\mathrm{mg}_{\mathrm{e}}, \mathrm{m}\right. \\
\left.\mathrm{min}^{-1}\right)\end{array}$ & $\begin{array}{c}\mathrm{B}_{\mathrm{k}}\left(\mathrm{mg}^{2}\right. \\
\left.\mathrm{min}^{-1} \mathrm{~L}^{-1}\right)\end{array}$ & \begin{tabular}{c}
$\mathrm{A}_{\mathrm{h}}\left(\mathrm{g} \mathrm{min}_{\left.\mathrm{mg}^{-1}\right)}\right.$ \\
\hline 0.0242
\end{tabular} & $\begin{array}{c}\mathrm{B}_{\mathrm{h}}(\mathrm{g} \\
\left.\mathrm{min} \mathrm{L}^{-1}\right)\end{array}$ \\
\hline
\end{tabular}

The generalized predictive model for basic blue 3 dye sorbed at any contact time and initial concentration within the given range with relationship of $\mathrm{q}_{\mathrm{e}}, \mathrm{C}_{\mathrm{o}}$ and $\mathrm{t}$ are as follows:

$$
q_{t}=\frac{C_{o} t}{A_{h} C_{o}+B_{h}+\left(A_{q} C_{o}+B_{q}\right) t}
$$

By substituting the calculated constant values into eqn. 8 , the theoretical model for basic blue 3-pomelo peel system could therefore be expressed as:

$$
\mathrm{q}_{\mathrm{t}}=\frac{\mathrm{C}_{\mathrm{o}} \mathrm{t}}{0.8997 \mathrm{C}_{\mathrm{o}}+19.403+\left(0.0242 \mathrm{C}_{\mathrm{o}}+4.849\right) \mathrm{t}}
$$

The theoretical model derived for basic blue 3 adsorption by pomelo peel was applied to obtain the adsorption capacity, $\mathrm{q}_{\mathrm{t}}$ at any given $\mathrm{C}_{\mathrm{o}}$ and $\mathrm{t}$. The plot of the comparison of the experimental data and the predicted theoretical values was shown in Fig. 7. It was evident that the theoretically generated curves showed a good agreement with the experimental data for adsorption of basic blue 3 dye cations by pomelo peel at concentrations of 20,30 and $40 \mathrm{mg} / \mathrm{L}$ and hence the pseudosecond order rate law provided a good prediction for the amounts of basic blue 3 adsorbed over the studied range.

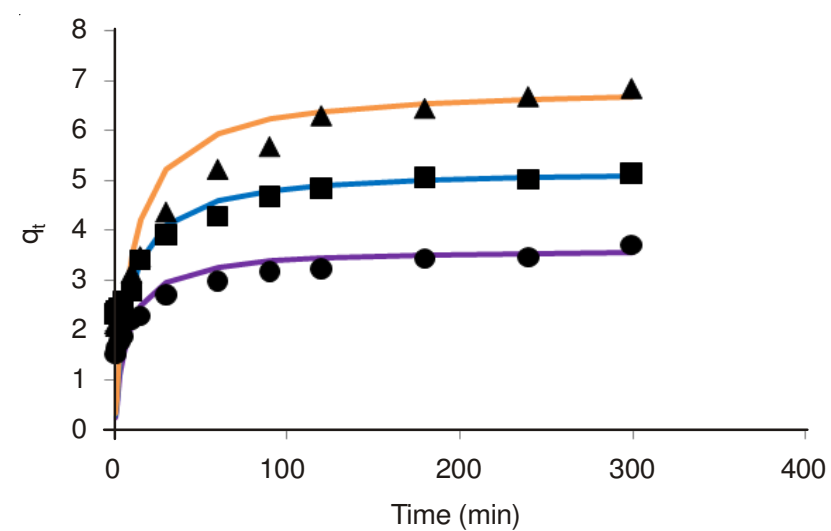

Fig. 7. Comparison between the measured and pseudo-second order modelled time profiles for basic blue 3 adsorption by pomelo peel. $\boldsymbol{\square}, \boldsymbol{\Delta}-20,30$ and $40 \mathrm{mg} / \mathrm{L}$ of basic blue 3 , Symbol experimental; Line - theoretical (5.0 g pomelo peel; dye volume 2 $\mathrm{L}$; natural $\mathrm{pH}$ of dye solution; $8 \mathrm{~h}$ )

Effect of pH: Fig. 8 shows the effect of solution $\mathrm{pH}$ on the percentage uptake of basic blue 3 dye by pomelo peel. It was found that the percentage uptake was minimum at $\mathrm{pH} 2$. There was a sharp increase in the percentage uptake from 4.31 to $33.69 \%$ at $\mathrm{pH} \mathrm{4}$, followed by a gradual increase in the synthetic dye uptake over the $\mathrm{pH}$ ranging 6-10. A similar trend was observed for the adsorption of methylene blue onto coconut bunch waste ${ }^{9}$.

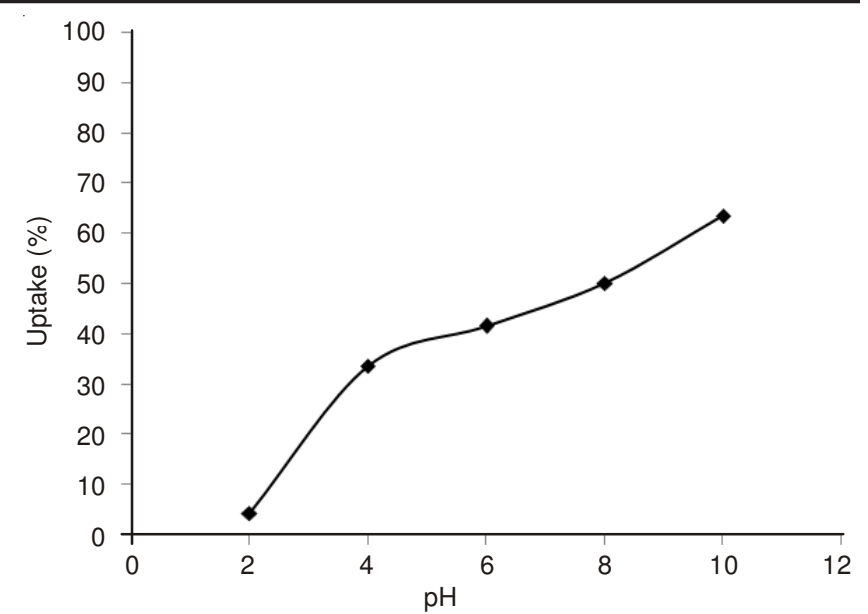

Fig. 8. Effect of solution $\mathrm{pH}$ on the percentage uptake of basic blue 3 by pomelo peel (5.0 g pomelo peel; dye volume $2 \mathrm{~L}$; natural $\mathrm{pH}$ of dye solution; $4 \mathrm{~h}$ )

The introduction of acids or basics could influence the surface charge of the adsorbents and the degree of ionization of adsorbate ${ }^{23}$. The low percentage uptake of basic blue 3 dye by pomelo peel at $\mathrm{pH} 2$ was due to the presence of excess $\mathrm{H}^{+}$ ions in the system. In acidic medium, the carboxyl groups on the surface of pomelo peel that are responsible for binding with basic blue 3 are predominantly protonated $(-\mathrm{COOH})$, hence incapable of binding basic blue 3 dye. However, as the $\mathrm{pH}$ of the system was increased, this facilitates a favourable sorption process due to the deprotonation of the carboxyl groups $\left(-\mathrm{COO}^{-}\right)$. The strong electrostatic attractive forces between the adsorbent and the adsorbate resulted in higher removal of basic blue 3 dye from the aqueous solution.

Sorption isotherms: Adsorption equilibrium study describes the interaction between the adsorbate and the adsorbent with a homogenous or heterogenous surface ${ }^{5}$. It is a dynamic concept achieved when the rate of the molecules adsorb onto a surface is equal to the rate they desorb. At equilibrium, no changes can be observed in the concentration of the solute on the adsorbent surface or in the dye solution ${ }^{24}$. The equilibrium adsorption equation isotherm is an equation relating the amount of solute adsorb onto the solid and the equilibrium concentration of the solute in solution at a given temperature.

To obtain information about the homogeneity and heterogeneity of the adsorbent surface, the adsorption kinetic of the adsorption of basic blue 3 dye onto pomelo peel was monitored by applying two commonly used adsorption isotherm models, namely Langmuir and Freundlich isotherm.

The linear form of Langmuir isotherm model is given by the following equation:

$$
\frac{\mathrm{C}_{\mathrm{e}}}{\mathrm{q}_{\mathrm{e}}}=\frac{\mathrm{C}_{\mathrm{e}}}{\mathrm{q}_{\mathrm{m}}}+\frac{1}{\mathrm{~K}_{\mathrm{L}} \mathrm{Q}_{\mathrm{o}}}
$$

whereas the linear form of Freundlich isotherm model can be represented as:

$$
\log \mathrm{q}_{\mathrm{e}}=\log \mathrm{K}_{\mathrm{F}}+(1 / \mathrm{n}) \log \mathrm{C}_{\mathrm{e}}
$$

where $\mathrm{q}_{\mathrm{e}}=$ the amount of dye adsorbed at equilibrium (mg/g), $\mathrm{Q}_{\mathrm{o}}=$ the maximum adsorption capacity $(\mathrm{mg} / \mathrm{g}), \mathrm{K}_{\mathrm{L}}=$ the adsorption equilibrium constant $(\mathrm{L} / \mathrm{mg}), \mathrm{C}_{\mathrm{e}}=$ the concentration 
of basic blue 3 dye solution at equilibrium $(\mathrm{mg} / \mathrm{L}), \mathrm{K}_{\mathrm{F}}=$ Freundlich constant for adsorption capacity $(\mathrm{mg} / \mathrm{g}), \mathrm{n}=$ Freundlich constant for intensity.

The linear plots of $\mathrm{C}_{\mathrm{e}} / \mathrm{q}_{\mathrm{e}}$ against $\mathrm{C}_{\mathrm{e}}$ and $\log \mathrm{q}_{\mathrm{e}}$ versus $\log$ $\mathrm{C}_{\mathrm{e}}$ for various basic blue 3 dye solution concentrations ranging from 20 to 90 mg/L are shown in Figs. 9 and 10, respectively. The isotherm parameters for removal of basic blue 3 dye by pomelo peel are listed in Table-3. It was found that Freundlich isotherm model provided a better correlation with high correlation coefficient of 0.9914 in comparison to Langmuir isotherm model. In the removal of basic and reactive dyes using EDTA modified rice hull, the sorption isotherm study also revealed that the experimental data fitted better into the Freundlich model as compared to Langmuir model ${ }^{25}$.

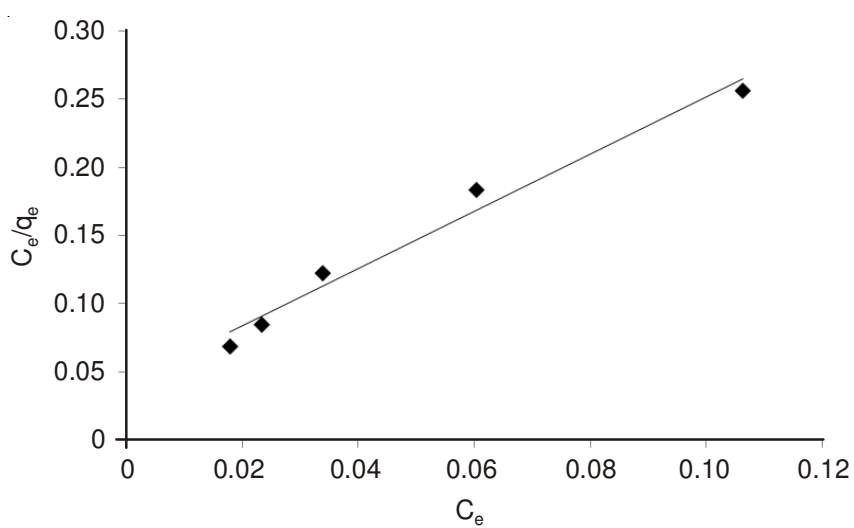

Fig. 9. Langmuir isotherm for the adsorption of basic blue 3 onto pomelo peel. (5.0 g pomelo peel; dye volume $2 \mathrm{~L}$; natural $\mathrm{pH}$ of dye solution; $4 \mathrm{~h})$

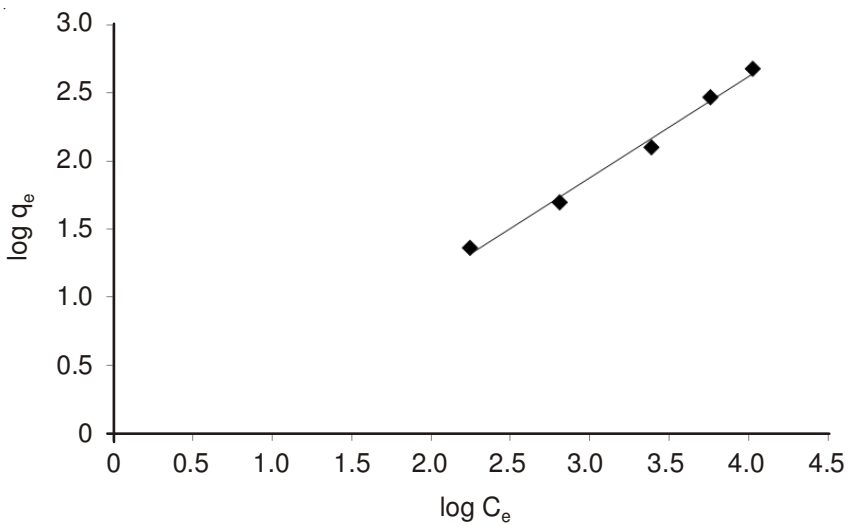

Fig. 10. Freundlich isotherm for the adsorption of basic blue 3 onto pomelo peel. (5.0 g pomelo peel; dye volume $2 \mathrm{~L}$; natural $\mathrm{pH}$ of dye solution; $4 \mathrm{~h})$

\begin{tabular}{|cc|ccc} 
TABLE-3 \\
ISOTHERM PARAMETERS FOR REMOVAL OF \\
BASIC BLUE 3 DYE BY POMELO PEEL \\
\hline \begin{tabular}{ccc|ccc}
\hline \multicolumn{3}{c|}{ Langmuir isotherm } & \multicolumn{3}{c}{ Freundlich isotherm } \\
\hline $\mathrm{Q}_{\mathrm{o}}\left(\mathrm{mg} \mathrm{g}^{-1}\right)$ & $\mathrm{K}_{\mathrm{L}}\left(\mathrm{L} \mathrm{mg}^{-1}\right)$ & $\mathrm{R}^{2}$ & $\mathrm{~K}_{\mathrm{F}}$ & $1 / \mathrm{n}$ & $\mathrm{R}^{2}$ \\
\hline 23.8663 & 0.02000 & 0.9772 & 0.7055 & 1.3468 & 0.9914 \\
\hline
\end{tabular}
\end{tabular}

Langmuir model implies monolayer coverage and constant sorption energy while the Freundlich model deals with physicochemical sorption on heterogeneous surfaces. However fitting the model to the sorption process does not necessarily imply any physical interpretation attached to them since the biosorbent's surface is non-homogeneous and there could be more than one type of sorption sites on the biosorbent's surface $^{26}$.

The essential characteristics of Langmuir isotherm can be expressed in terms of dimensionless constant separation factor for equilibrium parameter, $\mathrm{R}_{\mathrm{L}}$, which is defined as:

$$
\mathrm{R}_{\mathrm{L}}=\frac{1}{1+\mathrm{K}_{\mathrm{L}} \mathrm{C}_{\mathrm{o}}}
$$

The $\mathrm{R}_{\mathrm{L}}$ values for each initial concentration were tabulated in Table- 4 . The values $R_{L}$ decreased from 0.7219 to 0.3507 with increasing basic blue 3 dye concentration from 20 to 90 $\mathrm{mg} / \mathrm{L}$. The results indicated that the values skewed towards zero which represented the ideal irreversible case. Based on the calculated $R_{L}$ values shown in Table- 4 , this revealed that the adsorption of basic blue 3 onto pomelo peel was favourable.

\begin{tabular}{cc} 
TABLE-4 \\
VALUES OF $\mathrm{R}_{\mathrm{L}}$ FOR DIFFERENT BASIC BLUE 3 DYE \\
SOLUTION CONCENTRATIONS \\
\hline Initial concentrations (mg/L) & $\mathrm{R}_{\mathrm{L}}$ \\
\hline 20 & 0.7219 \\
30 & 0.6225 \\
50 & 0.4993 \\
70 & 0.4079 \\
90 & 0.3507 \\
\hline
\end{tabular}

The maximum adsorption capacity, $\mathrm{Q}_{\mathrm{o}}$ of pomelo peel from Langmuir equation was $23.87 \mathrm{mg} / \mathrm{g}$. Table-5 shows a comparison of the maximum adsorption capacity of pomelo peel with some other adsorbents in the removal of basic blue 3 dye from aqueous solutions reported in literature. From Freundlich isotherm equation, the isotherm intensity, $\mathrm{n}$ for pomelo peel was 1.3468. The magnitude of $\mathrm{n}$ gave an indication for the favourability of the adsorption. As the $\mathrm{n}$ is greater than 1 , this indicated that the adsorption system in this study was favourable.

\begin{tabular}{lcc} 
TABLE-5 & \\
A COMPARISON OF THE MAXIMUM ADSORPTION CAPACITY \\
\multicolumn{2}{c}{ OF POMELO PEEL WITH SOME OTHER ADSORBENTS } \\
\hline \multicolumn{1}{c}{ Adsorbent } & $\mathrm{Q}_{\mathrm{o}}(\mathrm{mg} / \mathrm{g})$ & Reference \\
\hline Corynebacterium glutamicum & 7.90 & {$[27]$} \\
Ethylenediamine modified rice hull & 3.29 & {$[28]$} \\
Natural durian peel & 49.50 & {$[16]$} \\
Natural sugarcane bagasse & 23.64 & {$[13]$} \\
Natural pomelo peel & 23.87 & This study \\
\hline
\end{tabular}

\section{Conclusion}

This finding identified pomelo peel as the potential lowcost adsorbent for the adsorption of basic blue 3 dye from aqueous solution. In the batch studies, the results indicated that adsorption capacity of pomelo peel was considerably affected by initial basic blue 3 dye concentrations, contact time and $\mathrm{pH}$. It was found that the percentage removal of dye was concentration dependent. Analysis of the kinetics data implied that pseudo-second order kinetics model provided a better correlation of the experimental results than pseudo-first order kinetic. The adsorption profiles derived based on the pseudosecond order kinetic model showed good agreement with the experimental curves. The effect on solution $\mathrm{pH}$ on dye uptake 
revealed that the percentage removal of dyes increased when the solution $\mathrm{pH}$ was increased. Equilibrium adsorption data conform to both Langmuir and Freundlich isotherms and maximum adsorption capacity was $23.87 \mathrm{mg} / \mathrm{g}$.

\section{ACKNOWLEDGEMENTS}

The financial support by the International Foundation of Science, Stockholm, Sweden and the Organization for the Prohibition of Chemical Weapons, The Hague, The Netherlands via Grant no. W/4368-1 and the research facilities by Universiti Tunku Abdul Rahman are acknowledged.

\section{REFERENCES}

1. K. Singh and S. Arora, Crit. Rev. Environ. Sci. Technol., 41, 807 (2011).

2. S.M. Lam, J.C. Sin, A.Z. Abdullah and A.R. Mohamed, Desalin. Water Treat., 41, 131 (2012).

3. M. Solis, A. Solis, H.I. Perez, N. Manjarrez and M. Flores, Process Biochem., 47, 1723 (2012).

4. E.N. El Qada, S.J. Allen and G.M. Walker, Chem. Eng. J., 124, 103 (2006).

5. M.A.M. Salleh, D.K. Mahmoud, W.A.W.A. Karim and A. Idris, Desalination, 280, 1 (2011).

6. A.E. Ofomaja, Process Biochem., 42, 16 (2007).

7. S.T. Ong, P.S. Keng, S.T. Ooi, Y.T. Hung and S.L. Lee, Asian J. Chem., 24, 398 (2012).

8. B.H. Hameed, J. Hazard. Mater, 162, 344 (2009).

9. B.H. Hameed, D.K. Mahmoud and A.I. Ahmad, J. Hazard. Mater., 158, 65 (2008).
10. M. Dogan, H. Abak and M. Alkan, J. Hazard. Mater., 164, 172 (2009).

11. G.Z. Kyzas, N.K. Lazaridis and A.C. Mitropoulos, Chem. Eng. J., 189190, 148 (2012).

12. P. Waranusantigul, P. Pokethitiyook, M. Kruatrachue and E.S. Upatham, Environ. Pollut., 125, 385 (2003).

13. S.T. Ong, E.C. Khoo, S.L. Hii and S.T. Ha, Desalin. Water Treatment, 20, 86 (2010).

14. M. Ertas, B. Acemioglu, M.H. Alma and M. Usta, J. Hazard. Mater, 183, 421 (2010).

15. K.Y. Foo and B.H. Hameed, Chem. Eng. J., 173, 385 (2011).

16. S.T. Ong, S.Y. Tan, E.C. Khoo, S.L. Lee and S.T. Ha, Desalin. Water Treatment, 45, 161 (2012).

17. B.H. Hameed, J. Hazard. Mater, 162, 939 (2009)

18. N. Nasuha, B.H. Hameed and A.T.M. Din, J. Hazard. Mater, 175, 126 (2010).

19. K.K. Singh, S.H. Hasan, M. Talat, V.K. Singh and S.K. Gangwar, Chem. Eng. J., 151, 113 (2009).

20. S. Lagergren and B.K. Svenska, Veternskapsakad Handlingar, 24, 1 (1898).

21. Y.S. Ho and G. McKay, Process Biochem., 34, 451 (1999).

22. Y.S. Ho, J. Hazard. Mater, 136, 681 (2006).

23. A. Ahmad, M. Rafatullah, O. Sulaiman, M.H. Ibrahim and R. Hashim, J. Hazard. Mater, 170, 357 (2009).

24. C.A.P. Almeida, N.A. Debacher, A.J. Downs, L. Cottet and C.A.D. Mello, J. Colloid Interf. Sci., 332, 46 (2009).

25. S.T. Ong, W.N. Lee, P.S. Keng, S.L. Lee, Y.T. Hung and S.T. Ha, Int. J. Phys. Sci., 5, 582 (2010).

26. B. Volesky, Biosorption and Biosorbents: In Biosorption of Heavy Metals, CRC Press Inc., Florida, USA. pp. 3-44 (1990).

27. K. Vijayaraghavan and Y.S. Yun, Biotechnol. Adv., 26, 266 (2008).

28. S.T. Ong, C.K. Lee and Z. Zainal, Bioresour. Technol., 98, 2792 (2007). 